\title{
Mobilization and Collection of HSC
}

\author{
Kai Hübel
}

\subsection{Introduction}

The intravenous infusion of patient's own HSC to restore $\mathrm{BM}$ damage is the basic principle of highdose chemotherapy, since otherwise the patient would expect long-lasting aplasia with lifethreatening infections. Therefore, a sufficient collection of HSC before application of highdose therapy is mandatory. Since HSC expresses CD34 on their surface, the number of CD34+ cells in the transplant material is considered as an indicator of the HSC content.

In principle, there are two ways how to collect stem cell: by repeated aspiration of BM from the pelvic crest or by leukapheresis after mobilization of HSC into the PB. The latter one is favored and considered as standard because it is less stressful for the patient and leads to faster engraftment and hematologic reconstitution which may improve patient outcomes (Gertz 2010).

Usually, HSC circulates in a very small number in the PB. Therefore, mobilization of HSC from the $\mathrm{BM}$ to the $\mathrm{PB}$ is an essential part of auto-HSCT programs. Following sufficient mobilization, patient will need leukapheresis which is often performed by central lines to facilitate the procedure. Finally, HSC will be cryopre-

K. Hübel $(\bowtie)$

University of Cologne, Department of Internal

Medicine, Cologne, Germany

e-mail: kai.huebel@uni-koeln.de served using dimethyl sulfoxide (DMSO) until transfusion.

\subsection{Strategies of Mobilization}

There are two different strategies to mobilize HSC from the BM to the PB: the so-called "steady-state" mobilization and the mobilization by chemotherapy.

\subsubsection{Mobilization Without Chemotherapy ("Steady State")}

Using this approach, HSC will be mobilized by the use of cytokines only. The only recommended cytokine for mobilization is G-CSF, since GM-CSF is no longer available in many countries after commercial failure and withdrawal. G-CSF induces myeloid hyperplasia and the release of $\mathrm{CD} 34+$ cells into the circulation through proteolytic cleavage of adhesion molecules (Lapidot and Petit 2002). Currently, the G-CSF cytokines filgrastim and lenograstim have market approval for mobilization of HSC in Europe.

The recommended doses are filgrastim $10 \mu \mathrm{g} /$ $\mathrm{kg}$ /day SC for 5-7 consecutive days and lenograstim $10 \mu \mathrm{g} / \mathrm{kg} /$ day $\mathrm{SC}$ for $4-6$ consecutive days. The use of biosimilar G-CSF has equivalent efficacy (Schmitt et al. 2016). 
Leukapheresis usually is performed on day 5 independent whether filgrastim or lenograstim was used for mobilization. The measurement of $\mathrm{CD} 34+$ cells in the PB before leukapheresis is not mandatory but could help to estimate the expected collection yield and the duration of leukapheresis. If the number of cells collected is inadequate, mobilization with G-CSF may be continued for 1-2 days. However, if the collection goal is not reached after the third leukapheresis, a successful mobilization is unlikely.

The major advantages of steady-state mobilization are the relatively low toxicity, the predictable time of leukapheresis, the outpatient administration, and the reduced costs compared to chemo-mobilization. The major disadvantages are variable mobilization failure rates and the lower CD34+ cell yields compared to chemo-mobilization. Mobilization with G-CSF only may be used in patients without further need of chemotherapy, e.g., in patients with a stable remission of the underlying disease.

\subsubsection{Mobilization with Chemotherapy}

The use of chemotherapy in combination with G-CSF is the preferred way of mobilization for all patients who will need further decrease of tumor burden and/or who have to collect a high number of HSC.

CY in a dose of $2-4 \mathrm{~g} / \mathrm{m}^{2}$ is widely used for HSC mobilization. It is also possible to mobilize HSC not by a separate chemotherapy but as part of the disease-specific chemotherapy, e.g., to mobilize HSC following salvage treatment with R-DHAP or R-ICE in lymphoma patients. The choice of a specific chemo-mobilization approach is based on patient's disease characteristics and local clinical practice guidelines.

Approved doses of G-CSF for HSC mobilization after myelosuppressive therapy are filgrastim $5 \mu \mathrm{g} / \mathrm{kg} /$ day $\mathrm{SC}$ and lenograstim $150 \mu \mathrm{g} / \mathrm{m}^{2} /$ day
SC. There are reports of the use of higher doses of G-CSF (Romeo et al. 2010), but there are no randomized trials and additional side effects are possible. Mobilization with G-CSF should start after completion of chemotherapy at the earliest and at the leukocyte nadir at the latest and should continue until the last leukapheresis. Most protocols recommend the initiation of G-CSF within 1-5 days after the end of chemotherapy.

The major advantage of adding chemotherapy to cytokines, besides the effect on the tumor, is the expected improvement of the collection yield with fewer apheresis sessions (Sung et al. 2013). The major disadvantages of chemomobilization are the therapy-related toxicity, the requirement of in-hospital treatment in most cases, the bone marrow damage by the chemotherapy which may impair future mobilizations, and higher mobilization costs. Furthermore, an exact prognosis of the CD34+ cell peak in the PB and the optimal start of leukapheresis are difficult and require daily monitoring of CD34+ cells in the PB. Table 15.1 summarizes a recommendation of timing of G-CSF following most used chemotherapy regimens and start of monitoring of CD34+ cells in the PB.

In several clinical trials, it was documented that relapse rate after auto-HSCT following mobilization with and without chemotherapy is comparable (Tuchman et al. 2015).

Table 15.1 Recommended start of G-CSF and start of CD34+ monitoring for most used mobilization chemotherapy regimens

\begin{tabular}{l|l|l|} 
Chemotherapy & Start G-CSF & $\begin{array}{l}\text { Start CD34+ } \\
\text { monitoring } \\
\text { Day } 10\end{array}$ \\
\hline CY $2 \mathrm{~g} / \mathrm{m}^{2}$ & Day 5 & Day 13 \\
\hline CAD & Day 9 & Day 11 \\
\hline R)CHOP/CHOEP & Day 6 & Day 14 \\
\hline R)DHAP & Day 9 & Day 12 \\
\hline R)ICE & Day 6 & Day 10 \\
\hline R)AraC/TT & Day 5 &
\end{tabular}

Day 1: first day of chemotherapy application (without rituximab). Adapted from (Kriegsmann et al. 2018) 


\subsection{CD34+ Cell Count and Timing of Leukapheresis}

Up to date, CD34+ cell count in mobilized peripheral blood product is the most important parameter of graft quality, as it is the only recognized predictor of stable hematopoietic engraftment after auto-HSCT (Saraceni et al. 2015). Monitoring of CD34+ cells in the PB is optional in steady-state mobilization but an essential part of chemo-mobilization. Following chemotherapy, the daily measurement of leukocytes and thrombocytes is recommended. If not otherwise specified by the protocol, CD34 monitoring should be initiated at the latest if leukocytes increase up to $1000 / \mu \mathrm{L}$ during recovering from aplasia. This increase of leukocytes is mostly accompanied with an increase of thrombocytes. A prompt start of leukapheresis is required of CD34+ cell count of $\geq 20 / \mu \mathrm{L}$ (Mohty et al. 2014); for more details, please see Sect. 15.6.

\subsection{Target HSC Collection Count}

The target quantity of HSC to be collected is dependent on the underlying disease. Most patients with NHL or HL (expect for rare case of patients with HL who require double auto-HSCT) will need one autograft. The generally accepted minimum CD34+ cell yield to proceed to transplantation is $2 \times 10^{6}$ cells $/ \mathrm{kg}$ (Mohty et al. 2014); however, higher yields of $4-5 \times 10^{6} \mathrm{CD} 34+$ cells/ $\mathrm{kg}$ are aimed for at many centers since they have been associated with faster neutrophil and platelet recovery, reduced hospitalization, blood transfusions, and antibiotic therapy (Stiff et al. 2011; Giralt et al. 2014). Patients mobilizing $>8-10 \times 10^{6}$ cells $/ \mathrm{kg}$ are called "super mobilizer"; however, the reported positive effect after infusion of such a high number of HSC on the outcome and prognosis of the patient is highly speculative. For patients with a chance of two or even more transplantations (mainly patients with $\mathrm{MM}$ ), it is essential to collect the required number of HSC before the first high-dose therapy since mobilization after high-dose therapy has an increased risk of failure. For tandem transplantation, the required cell dose for one transplantation is also at least $2 \times 10^{6} \mathrm{CD} 34+$ cells $/ \mathrm{kg}$.

\subsection{Leukapheresis}

Collection of peripheral HSC for auto-HSCT is a well-established process. The duration of one leukapheresis session should not exceed $5 \mathrm{~h}$, and the total number of leukapheresis session should not exceed four procedures since more sessions are useless in most cases and will stress the patient. CD34+ cell collection has been shown to be more effective with larger apheresis volume (4.0-5.3 times the patient's total blood volume), and no difference in CD34+ cell viability was observed compared with normal-volume apheresis (2.7-3.5 times the patient's total blood volume) (Abrahamsen et al. 2005). Enhanced volumes are especially recommended for patients with a high risk of mobilization failure or for patients with a high individual CD34+ cell collection goal. However, not all patients are eligible for enhanced volume strategies. Larger transfusion volumes and related higher DMSO contents have been associated with increased risk of cardiac side effects (Donmez et al. 2007).

\subsection{Poor Mobilizer}

Despite widespread and established practice, current mobilization strategies vary between centers and differ in terms of feasibility and outcome. Although the majority of patients are able to mobilize sufficient CD34+ cells for at least a single auto-HSCT, approximately $15 \%$ fail to do so (Wuchter et al. 2010). 
Poor mobilizers are usually defined as patients with less than $2 \times 10^{6} \mathrm{CD} 34+$ cells $/ \mathrm{kg}$ collected or patients mobilizing less than 10-20 CD34+ cells $/ \mu$ l into the PB. In general, there are two groups of poor mobilizers: predicted poor mobilizers and proven poor mobilizers (Olivieri et al. 2012). Proven poor mobilizers have low CD34+ peripheral counts circulating or do not achieve adequate HSC on day 1 of apheresis. Based on CD34+ cells, it is possible to identify the following subgroups: "borderline poor mobilizer" (11$19 \mathrm{CD} 34+$ cells $/ \mu \mathrm{L})$, "relative poor mobilizer" (6-10 CD34+ cells $/ \mu \mathrm{L})$, and "absolute poor mobilizer" (0-5 CD34+ cells $/ \mu \mathrm{L}$ ) (Wuchter et al. 2010). If a patient has $\geq 20 \mathrm{CD} 34+$ cells $/ \mu \mathrm{L}$ at time of apheresis, the collection process should start. Between 15 and $20 \mathrm{CD} 34+$ cells $/ \mu \mathrm{L}$, collection might be sufficient if not more than two transplantations are planned and the patient has no risk factors for poor mobilization (see below).

Otherwise, the use of plerixafor (recommended dose $0.24 \mathrm{mg} / \mathrm{kg} /$ day SC) should be considered. If a patient has $10-15 \mathrm{CD} 34+$ cells $/ \mu \mathrm{L}$, plerixafor application should be discussed. Below 10 CD34+ cells/ $\mu$ l, the use of plerixafor is clearly indicated to avoid mobilization failure. That means that there is a "gray area" between 10 and $20 \mathrm{CD} 34+$ cells/ $\mu \mathrm{L}$, and the decision to use plerixafor in this situation is based on disease characteristics and treatment history (Fig. 15.1). Furthermore, if it is not possible to collect at least one third of the collection goal with the first apheresis, plerixafor should be applied because of high risk of mobilization failure (Mohty et al. 2014; Cheng et al. 2015).

Predicted poor mobilizers are defined by baseline patient or disease characteristics which are

\section{$\mathrm{CD}^{2} 4^{+}$cell count prior to apheresis}

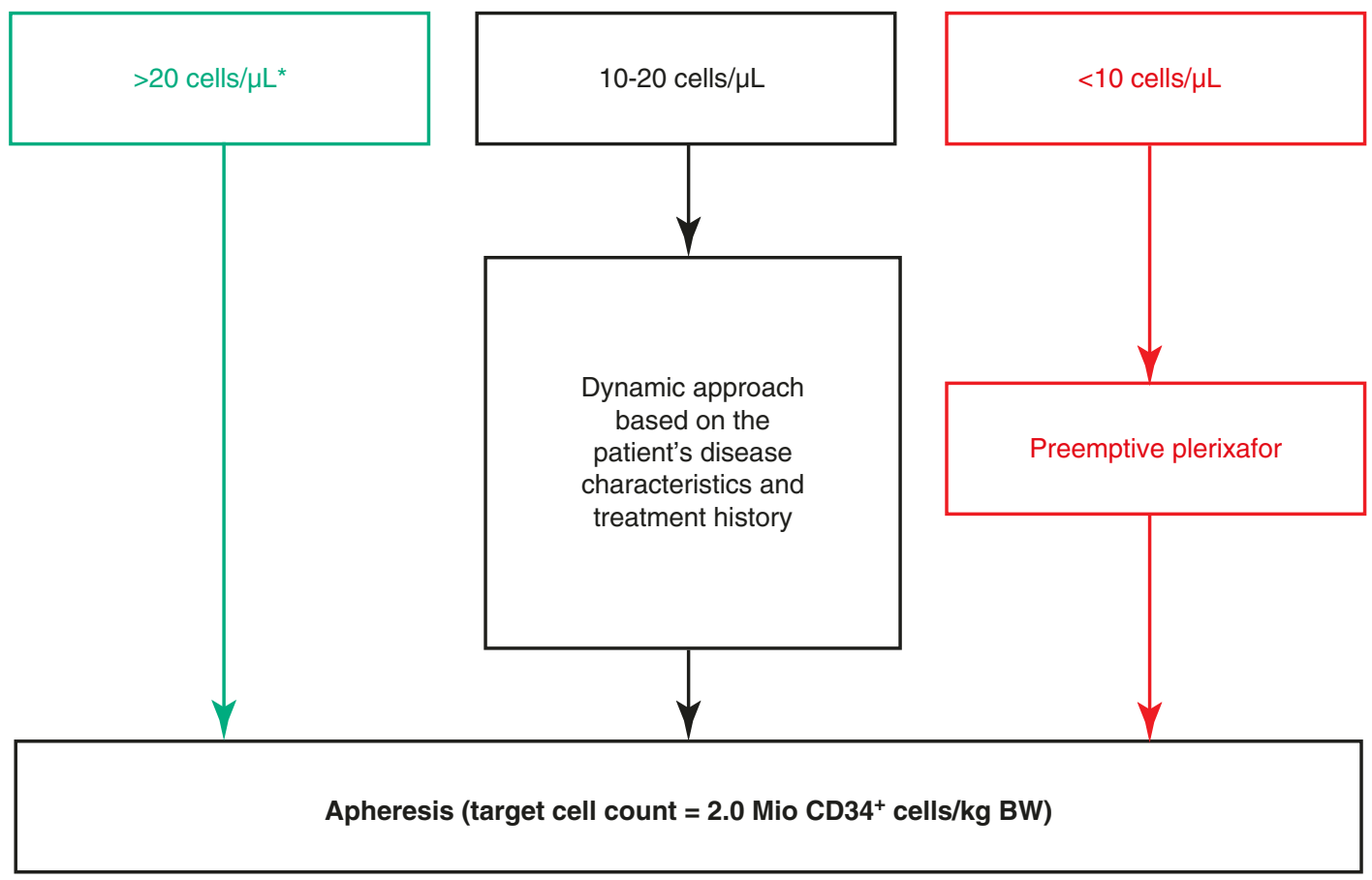

Fig. 15.1 Proactive intervention to rescue mobilization failure (Adapted from Mohty et al. 2014). *No active intervention required 
Table 15.2 Factors described as predictive of poor mobilization or mobilization failure

Risk factors for poor mobilization
Age $>60$ years
Advanced stage of underlying disease
High number of prior treatment lines
Therapy with fludarabine, melphalan, and lenalidomide
(controversial)
Low CD34+ cell count before apheresis
Low platelet count before mobilization (controversial)
Adapted from (Mohty et al. 2014)

associated with poor mobilization. These factors are listed in Table 15.2. In patients with one or more of these risk factors, the preemptive use of plerixafor should be considered. It is generally accepted that the most robust predictive factor for poor mobilization is the CD34+ cell count in PB before apheresis.

The use of plerixafor is not only valuable to avoid a failed mobilization in the described risk groups, bit it has also a documented effect on the resources of the centers. With the use of plerixafor, patients spend less time on apheresis with less blood volume processed and collect more CD34+ cells with the first apheresis, leading to a decreased number of apheresis sessions needed (Mohty et al. 2018). This has a direct effect on reducing mobilization costs. In case of a failed first mobilization attempt, the use of plerixafor for remobilization is clearly indicated (Hubel et al. 2011).

\subsection{Future Directions}

At this time, the number of CD34+ cells in the graft is the major and most important indicator for graft quality. A sufficient number of CD34+ cells are essential to overcome the toxicity of high-dose chemotherapy and to facilitate hematopoietic recovery. However, there is an increasing understanding that other graft subsets, e.g., CD34+ subpopulations or immune cell subsets (B cells, T cells, NK cells, dendritic cells), influence immune recovery. There are also reports that the mobilization regimen has a major impact on graft immune composition and patient's outcome (Saraceni et al. 2015). Therefore, stem cell mobilization could not only be an important part of high-dose therapies but could also be part of an effective immunotherapy. The delineation of this approach has just been started.

\section{Key Points}

- Mobilization with chemotherapy plus G-CSF is the preferred method for patients who will need decrease of tumor burden or who have to collect a high number of HSC.

- Up to date, CD34+ cell count in the PB is the most important parameter of graft quality.

- The required HSC dose for one transplantation is at least $2 \times 10^{6} \mathrm{CD} 34+$ cells $/ \mathrm{kg}$.

- The indication for the use of plerixafor depends on the CD34+ cell count in the $\mathrm{PB}$, the collection goal, the collection yield with the first apheresis, and/or the presence of risk factors.

\section{References}

Abrahamsen JF, Stamnesfet S, Liseth K, et al. Largevolume leukapheresis yields more viable CD34+ cells and colony-forming units than normal-volume leukapheresis, especially in patients who mobilize low numbers of CD34+ cells. Transfusion. 2005;45:248-53.

Cheng J, Schmitt M, Wuchter P, et al. Plerixafor is effective given either preemptively or as a rescue strategy in poor stem cell mobilizing patients with multiple myeloma. Transfusion. 2015;55:275-83.

Donmez A, Tombuloglu M, Gungor A, et al. Clinical side effects during peripheral blood progenitor cell infusion. Transfus Apher Sci. 2007;36:95-101.

Gertz MA. Current status of stem cell mobilization. Br J Haematol. 2010;150:647-62.

Giralt S, Costa L, Schriber J, et al. Optimizing autologous stem cell mobilization strategies to improve patient outcomes: consensus guidelines and recommendations. Biol Blood Marrow Transplant. 2014;20:295-308.

Hubel K, Fresen MM, Salwender H, et al. Plerixafor with and without chemotherapy in poor mobilizers: results from the German compassionate use program. Bone Marrow Transplant. 2011;46:1045-52.

Kriegsmann K, Schmitt A, Kriegsmann M, et al. Orchestration of chemomobilization and G-CSF administration for successful hematopoietic stem 
cell collection. Biol Blood Marrow Transplant. 2018;24:1281-8.

Lapidot T, Petit I. Current understanding of stem cell mobilization: the roles of chemokines, proteolytic enzymes, adhesion molecules, cytokines, and stromal cells. Exp Hematol. 2002;30:973-81.

Mohty M, Azar N, Chabannon C, et al. Plerixafor in poor mobilizers with non-Hodgkin's lymphoma: a multicenter time-motion analysis. Bone Marrow Transplant. 2018;53:246-54.

Mohty M, Hubel K, Kroger N, et al. Autologous haematopoietic stem cell mobilisation in multiple myeloma and lymphoma patients: a position statement from the European group for blood and marrow transplantation. Bone Marrow Transplant. 2014;49:865-72.

Olivieri A, Marchetti M, Lemoli R, et al. Proposed definition of 'poor mobilizer' in lymphoma and multiple myeloma: an analytic hierarchy process by ad hoc working group Gruppo Italiano Trapianto di Midollo Osseo. Bone Marrow Transplant. 2012;47:342-51.

Romeo A, Chierichini A, Spagnoli A, et al. Standard- versus high-dose lenograstim in adults with hematologic malignancies for peripheral blood progenitor cell mobilization. Transfusion. 2010;50:2432-46.

Saraceni F, Shem-Tov N, Olivieri A, Nagler A. Mobilized peripheral blood grafts include more than hematopoi- etic stem cells: the immunological perspective. Bone Marrow Transplant. 2015;50:886-91.

Schmitt M, Hoffmann JM, Lorenz K, et al. Mobilization of autologous and allogeneic peripheral blood stem cells for transplantation in haematological malignancies using biosimilar G-CSF. Vox Sang. 2016;111:178-86.

Stiff PJ, Micallef I, Nademanee AP, et al. Transplanted $\mathrm{CD} 34(+)$ cell dose is associated with long-term platelet count recovery following autologous peripheral blood stem cell transplant in patients with nonHodgkin lymphoma or multiple myeloma. Biol Blood Marrow Transplant. 2011;17:1146-53.

Sung AD, Grima DT, Bernard LM, et al. Outcomes and costs of autologous stem cell mobilization with chemotherapy plus G-CSF vs G-CSF alone. Bone Marrow Transplant. 2013;48:1444-9.

Tuchman SA, Bacon WA, Huang LW, et al. Cyclophosphamide-based hematopoietic stem cell mobilization before autologous stem cell transplantation in newly diagnosed multiple myeloma. J Clin Apher. 2015;30:176-82.

Wuchter P, Ran D, Bruckner T, et al. Poor mobilization of hematopoietic stem cells-definitions, incidence, risk factors, and impact on outcome of autologous transplantation. Biol Blood Marrow Transplant. 2010;16:490-9.

Open Access This chapter is licensed under the terms of the Creative Commons Attribution 4.0 International License (http://creativecommons.org/licenses/by/4.0/), which permits use, sharing, adaptation, distribution and reproduction in any medium or format, as long as you give appropriate credit to the original author(s) and the source, provide a link to the Creative Commons license and indicate if changes were made.

The images or other third party material in this chapter are included in the chapter's Creative Commons license, unless indicated otherwise in a credit line to the material. If material is not included in the chapter's Creative Commons license and your intended use is not permitted by statutory regulation or exceeds the permitted use, you will need to obtain permission directly from the copyright holder.

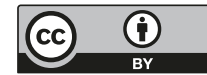

